\title{
Fast-Hardening Foam: Fire and Explosion Prevention at Facilities with Hazardous Chemicals
}

\author{
Gennady N. Kuprin ${ }^{1} \&$ Denis S. Kuprin ${ }^{2}$ \\ ${ }^{1}$ RPA «SOPOT», St. Petersburg, Russia \\ ${ }^{2}$ Laboratory of fire and explosion prevention, RPA «SOPOT», St. Petersburg, Russia \\ Correspondence: Gennady N. Kuprin, RPA «SOPOT», St. Petersburg, Russia. E-mail: dskuprin@mail.ru
}

Received: June 15, 2017

Accepted: June 27, 2017

Online Published: August 25, 2017

doi:10.5539/jmsr.v6n4p56

URL: https://doi.org/10.5539/jmsr.v6n4p56

\begin{abstract}
Analysis of the terroristic attacks in Siria, Afghanistan and other countries has shown high probability of the hazardous chemicals application by the terroristic groups. In the article the most catastrophic accidents which were connected with hazardous chemicals are described.

That is why research and developments in the sphere of protection from hazardous chemicals are still actual.

This article is dedicated to the new screening method of the spilled hazardous chemicals surface on the example of protection of the factories with these substances. Methodology, experimental apparatus, protective fast-hardening foam features, names of hazardous chemicals are shown.

Test were made for such chemicals as: acetic acid, acetone, ammonia, bromine, chlorbenzene, chloroform, hydrogen bromide, hydrogen chloride, hexane, hydrazine, diesel fuel, dichlorethane, kerosene, toluene, phenol, hydrogen fluoride. Fantastic results were achieved in terms of isolating capability of the fast-hardening foam against evaporations of the pointed substances.
\end{abstract}

\section{Introduction}

Industrial and technological progress today is occurring faster and faster. The reasons are growth of the industrial production volumes, complication of the technological processes, development and implantation of the high-tech and so on. All of that allow people around the world consume new benefits, use resources more effectively and raise their living standards eventually.

At the same time this trend has another side. There is industrial safety which does not keep up with industrial progress. And eventually safety of important and dangerous assets does not fit to requirements which are being created by technological progress speed. Evidently this situation may lead to the catastrophic consequences. And it happens indeed. For example:

\section{Some Accidents with Hazardous Chemicals Influence}

$21^{\text {st }}$ of September 2001, Toulouse, France. Explosion of 300 tones of ammonium nitrate $\left(\mathrm{NH}_{4} \mathrm{NO}_{3}\right)$ at the chemical factory AZF. 30 people were dead, 3000 people were injured, several thousand living houses and buildings were destroyed including 80 schools, 2 universities, 185 kindergartens. 40000 people became homeless; more than 130 enterprises were closed. Total losses cost is 3 billions Euros.

$22^{\text {nd }}$ of April 2010, Gulf of Mexico near the coast of Louisiana. Explosion and 36-hours fire killed 11 people and flooded controlled drilling platform Deepwater Horizon. Oil leakage was stopped only on $4^{\text {th }}$ of August. 5 million barrels of the raw oil were spilled to the Gulf of Mexico. Ecological losses are irreplaceable (figure 1). 


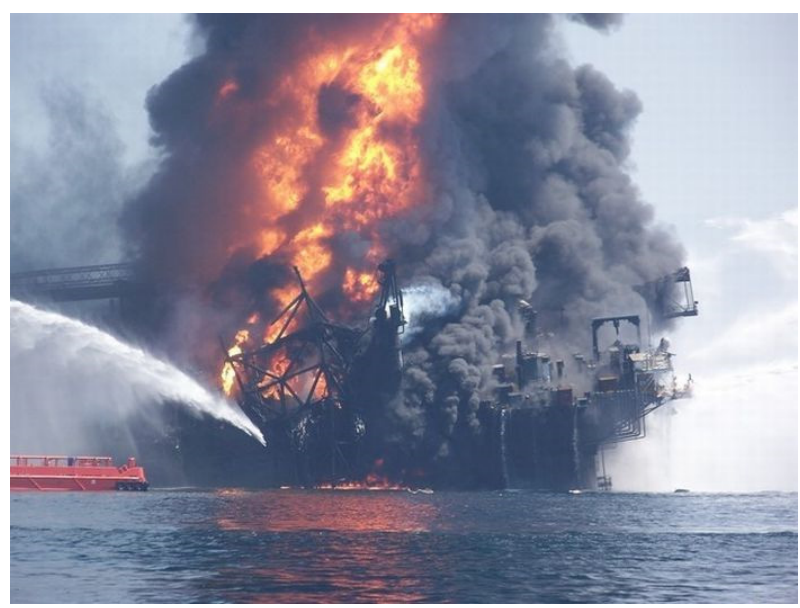

Figure 1. Flooding of the drilling platform in the Gulf of Mexico in result of explosion

$4^{\text {th }}$ of October 2010. Explosion at the aluminum production factory (west Hungary) has destroyed tank with toxic waste which is called "red sludge". About 1.1 million $\mathrm{m}^{3}$ flooded Kolontar and Dechever towns westward from Budapest. In the result of accident 10 people were dead and 150 people were injured (figure 2).

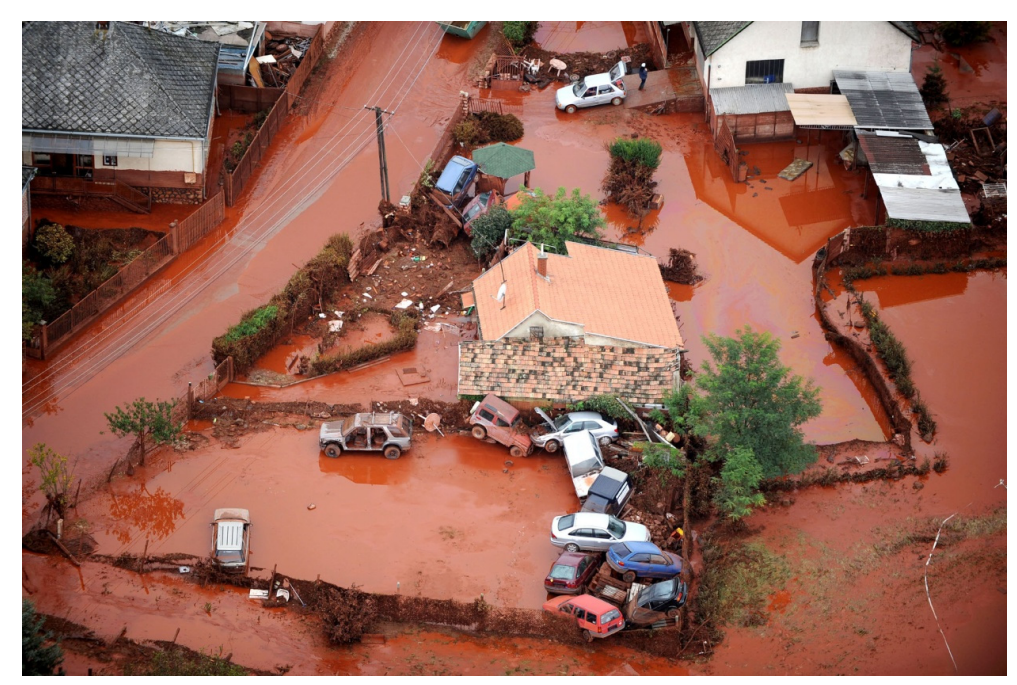

Figure 2. Red sludge leakage in Kolontar and Dechever towns (Hungary)

$1^{\text {st }}$ of September 2011, Chelyabinsk, Russia. Due to the fire in the freight car at the railway station tanks with high toxic substance bromine have been unsealed. In the result about 237 people asked a help, about 5 people were hospitalized.

$12^{\text {th }}$ of August 2015. Due to several strong explosions in Tianjin (China) hazardous chemicals concentration in the air exceeded the norm 27 times! About 114 people were dead, about 70 people disappeared, about 700 people were injured. Several hundred tones of the sodium cyanide were detected at the accident place (figure 3).

These catastrophes do not make the full list of accidents at all. They not only kill a lot of people but inflict irreparable damage to the Earth ecosystem as well which practically impossible to estimate.

Most victims at these accidents are caused by storage, production, transportation, usage of hazardous chemicals which break out and kill people and environment. 


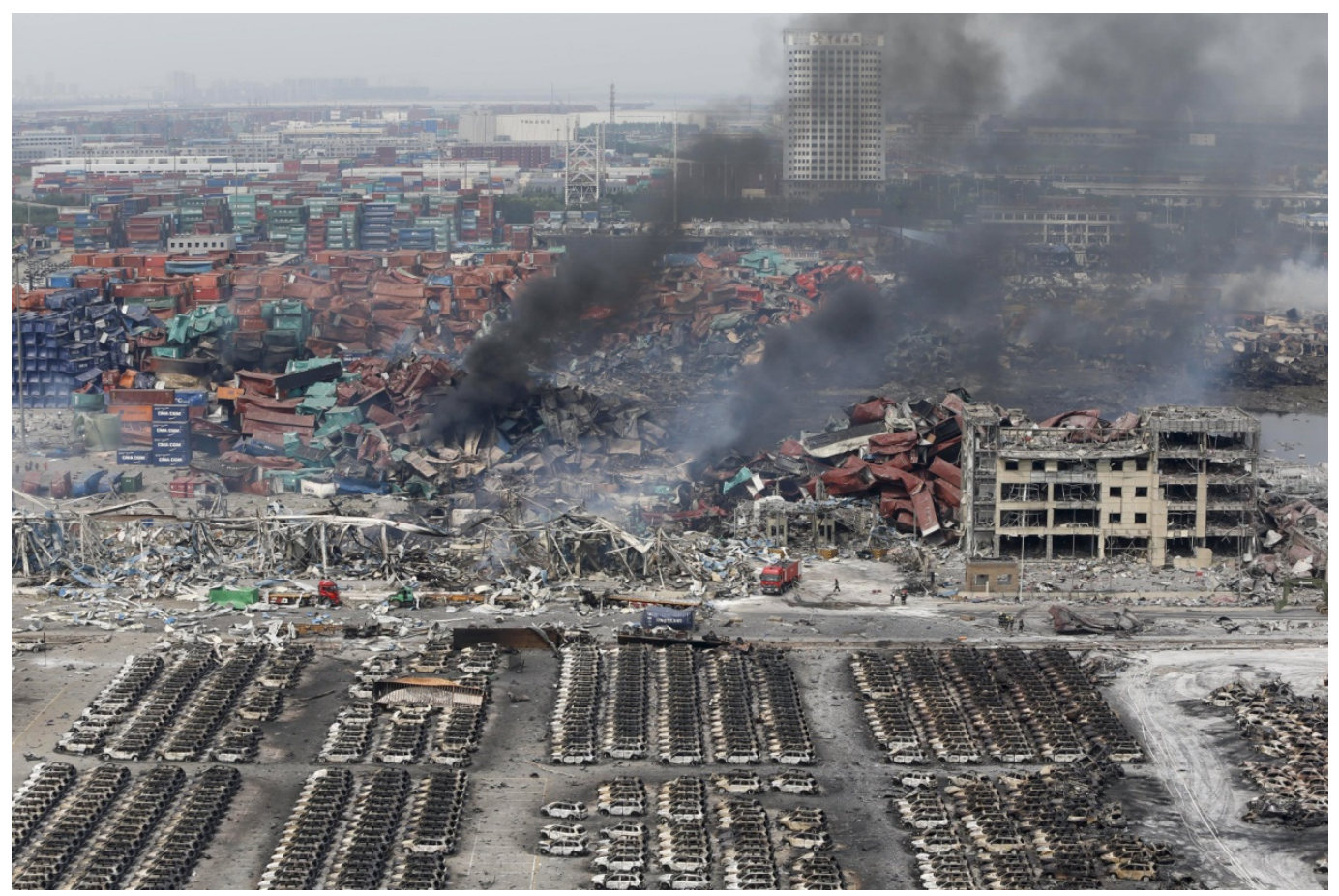

Figure 3. Consequences of explosion in Tianjin (China)

\section{Investigations of RPA "SOPOT"}

In 2015-2016 RPA "SOPOT" (St. Petersburg, Russia) has developed Fast-Hardening Foam (FHF) for fire and explosion prevention based on the structured silica particles $\left(\mathrm{SiO}_{2}\right)$. It is fire-extinguishing foam in which polymerization process is occurring during its generation and delivery to the fire object. This fact is caused by sol-gel transition which is well-known process in the colloidal chemistry. Thereby this foam becomes solid. At the same time it acquires absolutely new properties for any fire-fighting foams such as high adhesion, mechanical durability, thermal stability, heat and fire resistance and others. Besides FHF is fast degradable according to the GOST 32509-2013 what means that it is completely clean, biodegradable and environment friendly product. For delivery of FHF at the long distances there have been developed or modernized technical means with capacity from 1 to 100 Liters per second $(\mathrm{L} / \mathrm{s})$.

In 2017 laboratory of fire and explosion prevention (RPA "SOPOT") has made extensive investigations of isolating capability of FHF on the evaporative hazardous chemicals.

\section{Experimental Section}

Glasses were filled with hazardous chemical. Then its surface was covered with FHF. Then plastic container was inserted inside the top of the foam. Silicone tube was inserted in the hole of the plastic container from the side. This tube passed through the indicator tube and was connected with aspirator (figure 4).

With using of aspirator air above the foam layer was deflated through the silicone tube in the one-time intervals (1 hour) mode. Air volume and deflation time were determined according to the manuals for each indicator tube. When air passed through the indicator tube it was stained to another color (figure 5). Concentration of the hazardous chemicals vapors in the air above the foam layer was determined with indicator tubes. 


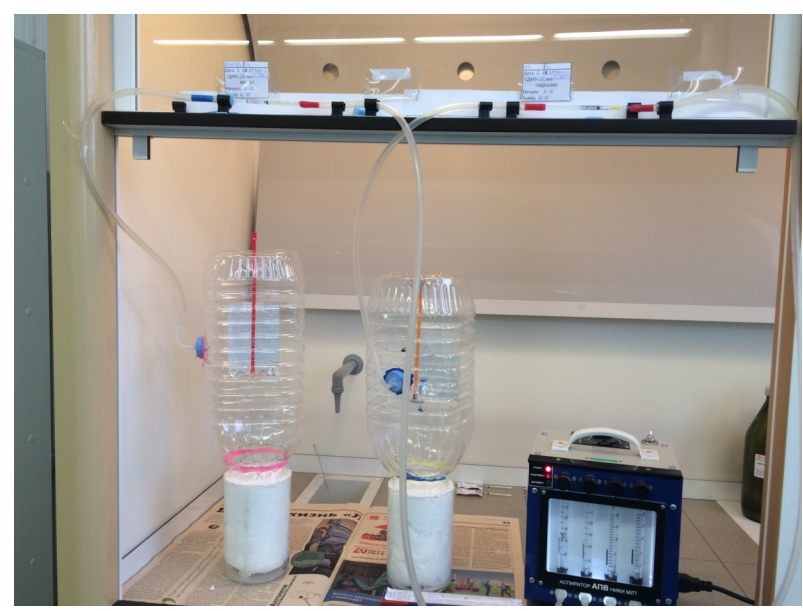

Figure 4. Measuring of the hazardous chemicals vapor concentration in the air above the foam layer

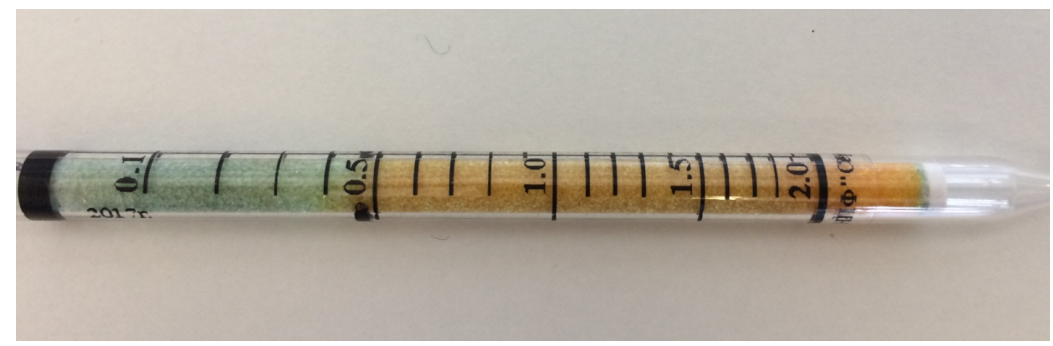

Figure 5. Indicator tube

Thereby isolating capability of the foam was determined. The lower hazardous chemicals vapors concentration in the air the higher isolating capability of the foam. Measured vapor concentration was compared with maximum permissible concentration (MPC) for the work zone on the one time mode.

After all measurements penetration coefficient was calculated according to the GOST R 12.4.262.2011 which shows weight of the substance which penetrates through the $1 \mathrm{~m}^{2}$ of protective foam layer for 1 second.

Results of investigations are presented in the Table 1:

Table 1. Results of investigations

\begin{tabular}{cccc}
\hline Substance & Chemical formula & $\begin{array}{c}\text { Time period of the vapor concentration } \\
\text { below MPC }\end{array}$ & $\begin{array}{c}\text { Penetration coefficient (averaged), } \\
\mathrm{mg} / \mathrm{m}^{2} \mathrm{~s}\end{array}$ \\
\hline Acetic acid & $\mathrm{CH}_{3} \mathrm{COOH}$ & $>6$ hours & 0 \\
Acetone & $\mathrm{C}_{3} \mathrm{H}_{6} \mathrm{O}$ & $>2$ hours & 58,7 \\
Ammonia & $\mathrm{NH}_{3}$ & $>6$ hours & 0,9 \\
Bromine & $\mathrm{Br}_{2}$ & $>6$ hours & 0 \\
Chlorbenzene & $\mathrm{C}_{6} \mathrm{H}_{5} \mathrm{Cl}$ & $>6$ hours & 0 \\
Chloroform & $\mathrm{CHCl}_{3}$ & $>6$ hours & 2,7 \\
Dichlorethane & $\mathrm{ClCH}_{2}-\mathrm{CH}_{2} \mathrm{Cl}$ & $>6$ hours & 0 \\
Diesel fuel & - & $>6$ hours & 22,4 \\
Hexane & $\mathrm{C}_{6} \mathrm{H}_{14}$ & $>6$ hours & 80,2 \\
Hydrazine & $\mathrm{N}_{2} \mathrm{H}_{4}$ & $>6$ hours & 0 \\
Hydrogen bromide & $\mathrm{HBr}$ & $>6$ hours & 0 \\
Hydrogen chloride & $\mathrm{HCl}$ & $>6$ hours & 0 \\
Hydrogen fluoride & $\mathrm{HF}$ & $>6$ hours & 0 \\
Kerosene & - & $>6$ hours & 10,3 \\
Toluene & $\mathrm{C}_{6} \mathrm{H}_{5}-\mathrm{CH}_{3}$ & $>6$ hours & 9,8 \\
Phenol & $\mathrm{C}_{6} \mathrm{H}_{6} \mathrm{O}$ & $>6$ hours & 0 \\
Petrol & - & & 8,7 \\
\hline
\end{tabular}


The same trials were made for several chemicals in the mode of their heating till $40^{\circ} \mathrm{C}$. Results were practically the same or even better than results of trials in the normal conditions mode.

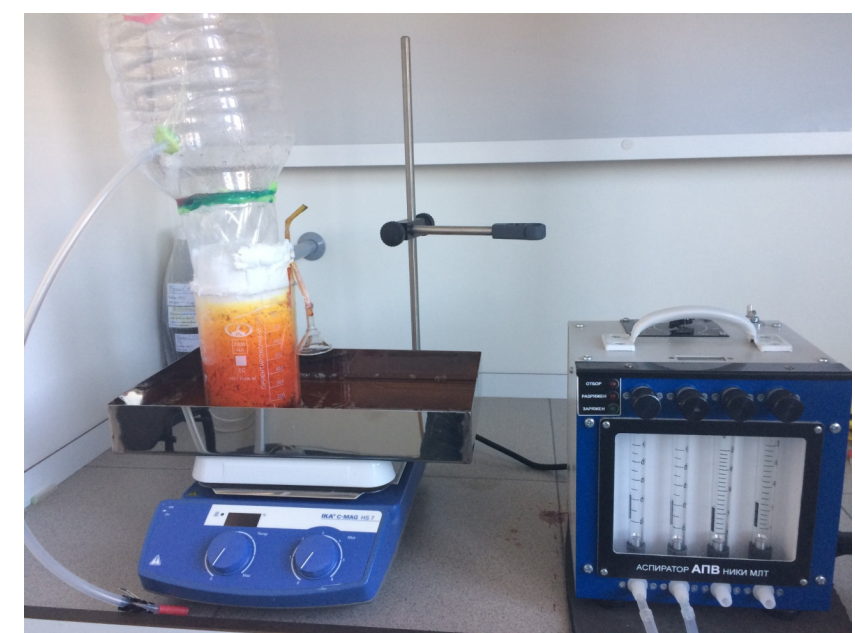

Figure 6. Measuring of the bromine vapor concentration in the air above the foam layer (temperature of bromine is $40^{\circ} \mathrm{C}$ )

Results of investigations are presented in the table 2:

Table 2. Results of investigations (temperature of chemicals is $40^{\circ} \mathrm{C}$ )

\begin{tabular}{cccc}
\hline Substance & Chemical formula & $\begin{array}{c}\text { Time period of the vapor } \\
\text { concentration below MPC }\end{array}$ & $\begin{array}{c}\text { Penetration coefficient (averaged), } \\
\mathbf{m g} / \mathbf{m}^{2} \mathbf{s}\end{array}$ \\
\hline Ammonia & $\mathrm{NH}_{3}$ & $>6$ hours & 0 \\
Bromine & $\mathrm{Br}_{2}$ & $>6$ hours & 0 \\
Hydrogen bromide & $\mathrm{HBr}$ & $>6$ hours & 0 \\
Hydrazine & $\mathrm{N}_{2} \mathrm{H}_{4}$ & $>6$ hours & 0 \\
Toluene & $\mathrm{C}_{6} \mathrm{H}_{5}-\mathrm{CH}_{3}$ & $>6$ hours & 0,6 \\
Acetic acid & $\mathrm{CH}_{3} \mathrm{COOH}$ & $>6$ hours & 0 \\
Hydrogen fluoride & $\mathrm{HF}$ & $>6$ hours & 0 \\
Hydrogen chloride & $\mathrm{HCl}$ & $>6$ hours & 0 \\
Chloroform & $\mathrm{CHCl}$ & $>4$ hours & 7,3 \\
\hline
\end{tabular}

\section{Conclusion}

1) Analysis of investigations results has shown that Fast-Hardening Foam based on structured silica particles is able to contain hazardous chemicals evaporation below MPC during the time period from 1 hour till more than 24 hours.

2) This time period is more than 6 hours for: ammonia, bromine, hydrogen bromide, hexane, hydrazine, diesel fuel, dichlorethane, kerosene, toluene, acetic acid, phenol, hydrogen fluoride, chlorbenzene, hydrogen chloride; more than $\mathbf{4}$ hours for: chloroform; more than 3 hours for: acetone.

3) During the heating of the hazardous chemicals till $40^{\circ} \mathrm{C}$ and maintaining of this temperature during the whole experiment time period of hazardous chemicals evaporation below MPC is more than $\mathbf{6}$ hours for: ammonia, bromine, hydrogen bromide, hydrazine, toluene, acetic acid, hydrogen fluoride, hydrogen chloride; more than 1 hour for: chloroform.

4) These investigations have proved that the covering of the hazardous chemicals with Fast-Hardening Foam based on structures silica particles allows to reduce sharply risk of the poisoning with hazardous chemicals vapors. Application of this technology allows to improve safety of rescue operations made by Emercom, Ministry of defense or special departments of industrial enterprises. 


\section{References}

GOST. (n.d.). GOST 12.1.005.88 Occupational safely standards system. General sanitary requirements for working zone air.

GOST. (n.d.). GOST R Occupational safely standards system. Protective clothing - Protection against chemicals - Determination of resistance of protective clothing materials to permeation by liquids and gases (MOD).

LLC "RPA “SOPOT”. (2015). Invention patent №2590379 "Foamed silica gel, application of foamed silica gel as fire extinguishing agent and sol-gel synthesis method thereof". Patent owner: LLC "RPA "SOPOT". Invention priority: 26.03.2015.

LLC "RPA “SOPOT”. (2015). International patent request PCT/RU2015/000819 "Foamed silica gel, application of foamed silica gel as fire extinguishing agent and sol-gel synthesis method thereof". Patent owner: LLC "RPA “SOPOT". Invention priority: 26.03.2015.

Abduragimov, I. M., Kuprin, G. N., \& Kuprin, D. S. (2016). Newest fire and explosion prevention technologies for facilities of the Head and Energy Complex with Fast-Hardening Foams based on structures silica particles. Safety, 2, 14-18.

Ternova, A., Grishkevich, A. A., and other. (2016). Investigation of protective features of the foam screens based on the specialized two-component composition. Report about research, 27 Science Centre, №5765. - 2016. $32 \mathrm{p}$.

NTV. (2015). Explosion in Tianjin [electronic resource]. Retrieved May 11, 2017, from http://www.ntv.ru/novosti/1468696

bigpicture. (2017). The largest technogenic catastrophes of the XXI century. Retrieved May 11, 2017, from http://bigpicture.ru/?p=425483

\section{Copyrights}

Copyright for this article is retained by the author(s), with first publication rights granted to the journal.

This is an open-access article distributed under the terms and conditions of the Creative Commons Attribution license (http://creativecommons.org/licenses/by/4.0/). 